\title{
Análise fitoquímica e atividade antifúngica do óleo essencial de folhas de Lippia sidoides Cham. e do Timol contra cepas de Candida spp
}

\author{
BRITO, D.I.V.1; MORAIS-BRAGA, M.F.B.1; CUNHA, F.A.B.1; ALBUQUERQUE, R.S.1; CARNEIRO, J.N.P.1; LIMA, \\ M.S.F.'; LEITE, N.F.'; SOUZA, C.E.S.'; ANDRADE, J.C.'; ALENCAR, L.B.B.'; LAVOR, A.K.L.S.'; FIGUEREDO, \\ F.G.'; LIMA, L.F.; COUTINHO, H.D.M. ${ }^{1 *}$. \\ Laboratório de Microbiologia e Biologia Molecular, Universidade Regional do Cariri, rua Cel. Antonio Luis 1161, \\ Pimenta, CEP 63105-000, Crato, Ceará, Brasil. *Autor para correspondência: hdmcoutinho@gmail.com
}

\begin{abstract}
RESUMO: A resistência de fungos do gênero Candida aos fármacos químicos tem lançado o desafio de se identificar novas substâncias que possuam atividade antibiótica ou venham a modular o efeito de produtos atualmente usados contra candidíase. O presente estudo avaliou a atividade antifúngica do óleo essencial de Lippia sidoides Cham. e do timol, sobre cepas de Candida. Inicialmente os produtos foram testados frente a 16 cepas fúngicas pela técnica de difusão em meio sólido, o que permitiu selecionar linhagens para continuidade da pesquisa. Com as linhagens de Candida krusei (CK LMBM 01, CK LMBM 02), Candida albicans (CA LM 62) e Candida tropicalis (CT LM 20), procedeu-se, por microdiluição em caldo, a determinação da Concentração Inibitória Mínima (CIM) e em meio sólido, a Concentração Fungicida Mínima (CFM) dos produtos foi identificada. O microcultivo das leveduras em meio empobrecido foi realizado para verificação de alterações morfológicas e, além disso, uma análise da composição química do óleo foi realizada por Cromatografia Gasosa acoplada à espectrometria de massas (CG-EM). Nesta análise, o constituinte majoritário foi o timol (84,95\%), seguido de compostos como p-cimeno e Éter metil carvacrol, entre outros. A CIM do óleo essencial de Lippia sidoides Cham. frente às cepas variou entre 64 e $256 \mu \mathrm{g} / \mathrm{mL}$, enquanto a CIM do timol foi estabelecida entre 32 e $64 \mu \mathrm{g} / \mathrm{mL}$. A CFM do óleo essencial foi determinada entre 128 e $512 \mu \mathrm{g} / \mathrm{mL}$ e para o timol foram encontrados valores entre 64 e $128 \mu \mathrm{g} / \mathrm{mL}$. Em relação à análise micromorfológica, verificada nas concentrações de CIM e CIM x 2, o óleo essencial inibiu o dimorfismo das cepas CK 01 e CT 20 na CIM e quando foi ensaiado o timol, este, na CIM, impediu a transição morfológica das cepas CK 01 e CA 62. Uma redução da morfogênese também foi obsevada na cepa CT 20, porém apenas em CIM x 2 e de forma mais discreta. Os resultados enaltecem o potencial antifúngico de L. sidoides e de seu composto majoritário timol tanto no combate à Candida quanto na neutralização de um dos fatores de virulência, a capacidade invasiva por formação de hifas e pseudohifas verificado na condição patogênica da candidíase. Estes dados são promissores e poderão incentivar futuras pesquisas sobre os aspectos fitoquímicos, toxicológicos e farmacológicos tanto do óleo essencial de Lippia sidoides como também de seus componentes químicos.
\end{abstract}

Palavras-chaves: Lippia sidoides, timol, atividade antifúngica, inibição de virulência.

\begin{abstract}
Phytochemical analysis and antifungal activity of the essential oil of Lippia sidoides Cham. and of the Thymol against Candida strains. The resistance of the Candida against drugs has been a challenge to the discovery of new substances with antimicrobial or modulatory effects that could be used against the cadidiasis. This work evaluated the antifungal activity of the essential oil of Lippia sidoides Cham. and of the Thymol against Candida strains. The products were tested towards 16 strains of Candida using the diffusion method, which allowed to select the strains in order to proceed with the research. The strains of Candida krusei (CK LMBM 01, CK LMBM 02), Candida albicans (CA LM 62) and Candida tropicalis (CT LM 20) were assayed by the microdilution method so that the Minimal Inhibitory Concentration (MIC) and the Minimal Fungicide Concentration (MFC) could be determined. The morphogenesis of the Candida was evaluated using poor environment in order to observe morphological changes. The composition of the essential oil was determined by GC-MS. The main compound
\end{abstract}


observed was the thymol (84.95\%). The MIC of the essential oil of L. sidoides and Thymol ranged between 64 to $256 \mu \mathrm{g} / \mathrm{mL}$, and between 32 to $64 \mu \mathrm{g} / \mathrm{mL}$ respectively. The MFC of the essential oil and the thymol varied between 128 to $512 \mu \mathrm{g} / \mathrm{mL}$ and 64 to $128 \mu \mathrm{g} / \mathrm{mL}$ respectively. The morphogenesis of different Candida strains was inhibited in the MIC and MICx2 to the essential oil and thymol. The results indicated the antifungal potential of the $L$. sidoides and of the Thymol due to the inhibition of the invasive capacity, one of the most important virulence factors for the candidiasis' development. These results are promising to new researches about the phytochemical, toxicological and pharmacological aspects of the essential oil of $L$. sidoides and its phytochemical compounds.

Keywords: Lippia sidoides, thymol, antifungal activity, inhibition of virulence.

\section{INTRODUÇÃO}

Nas infecções fúngicas, as leveduras do gênero Candida são as mais comuns causadoras de micoses superficiais ou invasivas em seres humanos (Dignani et al., 2003). As espécies de Candida colonizam as mucosas de todos os seres humanos durante ou após o nascimento, existindo sempre o risco de infecção endógena. A candidíase é a micose mais comum, sendo os agentes causadores mais frequentes a Candida albicans, C. tropicalis, C. parapsilosis, C. glabrata, C. guilliermondii e C. dubliniensis (Micthell, 2009).

Lippia sidoides Cham., conhecida popularmente como alecrim-pimenta, alecrimdo-nordeste e estrepa-cavalo, pertencente à família Verbenaceae, é um arbusto caducifólio, ereto, bastante ramificado e quebradiço, de 2-3 $\mathrm{m}$ de altura, próprio da vegetação do semi-árido nordestino do Brasil (Lorenzi \& Matos, 2002). O óleo essencial obtido das folhas dessa planta possui uma ampla diversidade química, tendo como principal componente o timol, com teor variando entre 34,2 a 95,1\% em várias determinações (Leal et al., 2003). São nas folhas que se encontra até $4,5 \%$ de óleo sendo o timol responsável por seu cheiro característico (Matos, 2002).

Os óleos essenciais são compostos voláteis naturais, possuem como característica forte odor e são produzidos por plantas aromáticas a partir do metabolismo secundário e contém de 20 a 60 constituintes em diversas concentrações. São conhecidos pela fragrância e por possuírem propriedades fungicidas, bactericidas, antivirais e medicinais, podendo ser empregados como antimicrobianos, analgésicos, sedativos e antiinflamatórios (Bakkali, 2008).

Diversos estudos têm evidenciado o efeito de compostos isolados, extraídos a partir de óleos essenciais de plantas, que agem como fungicidas naturais, inibindo a atividade fúngica, dentre os quais, um número bastante significativo destes constituintes se mostrou eficaz (Abdelgaleil et al., 2008). Os constituintes químicos dos óleos essenciais variam desde hidrocarbonetos terpênicos, fenóis, alcoóis simples, éteres, ésteres, aldeídos, ácidos orgânicos, cetonas, lactonas, cumarinas, até compostos contendo nitrogênio e enxofre (Simões et al., 2004).

Diante destas considerações, o presente estudo teve como finalidade avaliar a atividade antifúngica, in vitro, do óleo essencial de Lippia sidoides Cham. (alecrim-pimenta) e de seu composto majoritário timol frente a cepas de Candida, bem como avaliar o potencial destes produtos na redução da virulência de espécies do gênero Candida, por meio da alteração no dimorfismo celular das leveduras.

\section{MATERIAIS E MÉTODOS \\ Seleção e coleta do material botânico}

O material botânico de Lippia sidoides Cham. foi coletado no Horto de Plantas Medicinais, do Laboratório de Pesquisas de Produtos Naturais - LPPN, da Universidade Regional do Cariri URCA Coordenadas: 07 14' 19,2" de latitude Sul e $39^{\circ} 24^{\prime}$ 52,8" de longitude West de Greenwich. As folhas foram selecionadas e postas pra secar a sombra e temperatura ambiente $\left(25^{\circ} \mathrm{C}\right)$. Cinco ramos compostos de folhas e flores foram separados para preparação da exsicata, que foi depositada no Herbário Caririense Dárdano de Andrade Lima, da Universidade Regional do Cariri - URCA, sob o número de herbário 8096.

\section{Extração de óleo essencial}

Folhas frescas de Lippia sidoides Cham. foram coletadas as 09:00 horas, \pm 30 minutos, $500 \mathrm{~g}$ desse material foi picotado, com tesoura, em pedaços de aproximadamente $1 \mathrm{~cm}^{2} \mathrm{e}$ imersas em água destilada, em balão de vidro de 5 litros, sendo submetidas a extração com aparelho de Clevenger a uma temperatura de $100^{\circ} \mathrm{C}$, durante 2 horas (modificado a partir de Gottlieb, 1960), obtendo-se $2,5 \mathrm{~g}$ de óleo essencial, correspondente a um rendimento de $0,5 \%$. O óleo foi submetido à Cromatografia Gasosa, acoplada a Espectrometria 
de Massa - CG-EM, para identificação de seus fitoconstituintes.

\section{Análise do óleo essencial por CG-EM}

A análise do óleo foi realizada utilizando um Shimadzu CG/EM - série QP2010 (sistema CG/ EM): coluna capilar Rtx-5MS ( $30 \mathrm{~m} \times 0,25 \mathrm{~mm}, 0,25$ $\mu \mathrm{m}$ de espessura do filme), o gás hélio a $1,5 \mathrm{~mL} /$ min, temperatura do injetor $250^{\circ} \mathrm{C}$; temperatura do detector $290^{\circ} \mathrm{C}$, temperatura da coluna $60^{\circ} \mathrm{C}-180$ ${ }^{\circ} \mathrm{C}$ a $5^{\circ} \mathrm{C} / \mathrm{min}$, em seguida, $180^{\circ}-280^{\circ} \mathrm{C}$ a $10^{\circ} \mathrm{C} /$ $\min$ (10 min). Velocidade de digitalização foi de 0,5 scan/seg de $\mathrm{m} / \mathrm{z} 40$ e 350 . Relação Split (1:200). Volume injetado: $1 \mu \mathrm{L}$ de [25 $\mu \mathrm{L}$ (óleo essencial) / 5 $\mathrm{mLCHCl}_{3}$ ] (1:200). Tempo de corte do solvente $=2,5$ min. O espectrômetro de massas foi operado com $70 \mathrm{eV}$ de energia de ionização. Os componentes individuais foram identificados por correspondência dos seus espectros de massas com os da base de dados usando a biblioteca de espectro de massa NIST 08, índices de retenção, e comparação com os dados publicados (Adams, 2001).

\section{Micro-organismos}

Para os ensaios de atividade antifúngica do óleo essencial de L. sidoides e do timol, foram utilizadas um total de 16 cepas de fungos leveduriformes das espécies $C$. albicans, $C$. tropicalis e $C$. krusei isoladas de amostras biológicas, codificadas como CA LM 12, CA LM 62, CA LM 77, CA LM 106, CA LM 108, CA LM 109, CA LM 111, CA LM 122, CT LM 06, CT LM 10, CT LM 14, CT LM 18, CT LM 20, CT LM 23, cedidas pela Dra. Edeltrudes Oliveira Lima do Laboratório de Micologia da Universidade Federal da Paraíba (UFPB-PB) e as cepas CK LMBM 01 e CK LMBM 02 isoladas no Laboratório de Microbiologia e Biologia Molecular (LMBM) da Universidade Regional do Cariri. Todas as linhagens foram mantidas em tubos de ensaio contendo Ágar Sabouraud Dextrose (ASD) inclinado, sob refrigeração $\left(4^{\circ} \mathrm{C}\right)$.

\section{Meios de Cultura}

Foram utilizados nos ensaios para avaliação da atividade antifúngica o meio sólido Ágar Sabouraud Dextrose (ASD) e o meio líquido Caldo Sabouraud Dextrose (CSD), adquiridos da Difco ${ }^{\circledR}$ e preparados de acordo com as instruções do fabricante. O Ágar-arroz foi produzido segundo Sidrim \& Rocha (2010), com água destilada e esterilizados em autoclave, a $121^{\circ} \mathrm{C}$ por 15 minutos. O timol cristalizado foi gentilmente cedido pelo Laboratório Synth, São Paulo, Brasil.

\section{Inóculo}

Para o procedimento de preparação do inóculo dos fungos, primeiramente os isolados foram cultivados em meio ASD inclinado a $37{ }^{\circ} \mathrm{C}$ por $24 \mathrm{~h}$ (overnight). Inicialmente foram preparadas suspensões dos micro-organismos em tubos contendo $5 \mathrm{~mL}$ de solução estéril $(\mathrm{NaCl}$ a $0,9 \%)$. Em seguida, essas suspensões foram agitadas por 2 minutos com auxílio do aparelho Vortex. Após agitação, cada suspensão teve sua turbidez comparada e ajustada àquela apresentada pela suspensão de sulfato de bário do tubo 0,5 da escala de McFarland, a qual corresponde a um inóculo de aproximadamente $10^{8}$ Unidades Formadoras de Colônias $/ \mathrm{mL}$ - UFC/mL (Cleeland \& Squires, 1991; Hadacek \& Greger, 2000; Souza et al., 2007).

\section{Screening}

O óleo essencial e o timol foram solubilizados inicialmente em dimetilsulfóxido (DMSO) e posteriormente em água destilada a fim de obter uma solução estoque na concentração desejada. O ensaio foi realizado de acordo com Coutinho et al. (2008), pelo método da difusão em cavidades realizado em placas de Petri com ASD, nas quais foram inoculados os fungos e perfuradas cavidades de $6 \mathrm{~mm}$, seladas posteriormente com meio ASD fundido e preenchidas com $50 \mu \mathrm{L}$ do óleo diluído ou timol ( $10.000 \mu \mathrm{g} / \mathrm{mL})$, sendo levadas posteriormente à incubadora $\left(37^{\circ} \mathrm{C}\right)$ por $24 \mathrm{~h}$. Foi realizado um controle com DMSO para descartar a interferência do mesmo no resultado. Após a incubação procedeu-se a verificação do diâmetro dos halos de inibição, onde as maiores medidas (acima de $5 \mathrm{~mm}$ ) direcionaram a seleção das linhagens para realização da pesquisa.

\section{Determinação da Concentração Inibitória Mínima (CIM)}

A determinação da CIM do óleo essencial de $L$. sidoides e do timol foi realizada pela técnica de microdiluição, utilizando placas contendo 96 cavidades com fundo em forma de "U" e em triplicata (Ellof, 1998; Souza et al., 2007). Em cada orifício da placa foi adicionado $100 \mu \mathrm{L}$ do meio líquido CSD duplamente concentrado contendo, neste, $10 \%$ de suspensão fúngica em salina. A placa foi preenchida no sentido numérico e em seguida foram adicionados $100 \mu \mathrm{L}$ do óleo essencial, previamente diluído, no primeiro poço de cada coluna da placa, procedendo-se a microdiluição seriada com a solução de $100 \mu \mathrm{L}$ do produto natural, onde as concentrações variaram de 1024 a $1 \mu \mathrm{g} / \mathrm{mL}$. O último poço foi destinado ao controle de crescimento de micro-organismos. Um controle com DMSO (10\%) foi realizado para confirmação de atividade restrita aos produtos. As placas foram levadas à estufa por 24 h a $37^{\circ} \mathrm{C}$ (Javadpour et al., 1996). A revelação da CIM foi feita pela observação da turbidez provocada pelo crescimento. A CIM para os produtos testados

Rev. Bras. PI. Med., Campinas, v.17, n.4, supl. II, p.836-844, 2015. 
foi definida como a menor concentração capaz de inibir visualmente o crescimento fúngico verificado nos orifícios, quando comparado com o crescimento controle (NCCLS, 2002).

\section{Determinação da Concentração Fungicida Mínima (CFM)}

A concentração fungicida mínima foi realizada a partir de cada inóculo do teste anterior que não apresentou crescimento e os controles positivos. Uma alçada de cada poço, ou seja, dos poços onde foram determinadas as CIMs, foi subcultivada em placas de Agar Sabouraud Dextrose, devidamente identificadas. Após 24 horas de incubação a $35 \pm 2{ }^{\circ} \mathrm{C}$, realizou-se leitura, com a finalidade de observação do crescimento das colônias. As leituras das CFMs foram realizadas com base no crescimento dos controles, sendo considerada CFM, a menor concentração da droga que impediu crescimento visível do subcultivo (Shadomy et al., 1985).

\section{Efeito do óleo essencial de Lippia sidoides} Cham. e do Timol sobre a micromorfologia de Candida

Para observação de alterações morfológicas das cepas de Candida foi empregada a técnica do microcultivo para leveduras, utilizando o meio ágararroz em câmara úmida (Sidrim \& Rocha, 2010; Kurtzman \& Fell, 1998). Foram considerados os resultados obtidos na determinação da CIM dos produtos avaliados sobre as mesmas cepas deste estudo e adicionadas quantidades suficientes das emulsões do óleo essencial de $L$. sidoides e do Timol ao meio de cultura ágar-arroz, nas variadas concentrações dos produtos, no referido meio (CIM, $\mathrm{CIM} \times 2$ ).

Foi depositado $2 \mathrm{~mL}$ de ágar-arroz, associados aos produtos testes, nas respectivas concentrações, fundidos sobre uma lâmina estéril, contida sobre um suporte (outra lâmina) dentro de uma placa de Petri. Após solidificação do meio, foi semeada a levedura, com auxílio de uma alça calibrada níquel-cromo de $1 \mu \mathrm{L}(0,001 \mathrm{~mL})$, fazendo duas estrias paralelas. As estrias foram cobertas com lamínulas esterilizadas. Para evitar ressecamento do meio, foi preparada uma câmara úmida, acrescentando $1 \mathrm{~mL}$ de água destilada sobre um pedaço de papel filtro $(3 \times 3 \mathrm{~cm})$ estéril na placa, durante o período de incubação. Decorrido o tempo de incubação (24 h a $37^{\circ} \mathrm{C}$ ), cada preparação foi examinada em microscopia óptica, com aumento de 40x, para a observação de possíveis alterações na morfologia fúngica, quanto à formação de hifas e pseudohifas, importante fator de virulência fúngica. As Imagens dos microcultivos foram captadas por câmera fotográfica com zoom de $4 \mathrm{x}$.

\section{RESULTADOS}

Através da realização da Cromatografia Gasosa acoplada à espectrometria de massas (CG-EM) onde foi avaliado o óleo essencial obtido das folhas de L. sidoides foi possível identificar fitoconstituíntes existentes no produto natural apresentados na (tabela 1), revelando como componente majoritário, o timol, com uma concentração de $84,95 \%$. Outros compostos também foram detectados, porém em percentuais inferiores. Nesta análise realizada, o predomínio foi de compostos monoterpênicos.

No screening realizado pelo método de difusão por cavidade, foram selecionadas as linhagens CK LMBM 01, CK LMBM 02, CA LM 62 e CT LM 20 para as quais os produtos testados mostraram melhor efeito, com halos de inibição variando entre 5 e $6 \mathrm{~mm}$.

A realização do ensaio para determinação da CIM do óleo essencial de L. sidoides (OELS), revelou potencial antifúngico com efeito inibidor observado nas concentrações que variavam entre 64 e $256 \mu \mathrm{g} / \mathrm{mL}$, enquanto a CIM do timol variou entre 32 e $64 \mu \mathrm{g} / \mathrm{mL}$ (Tabela 2).

Tanto o óleo quanto o timol demonstraram efeito fungicida onde a Concentração Fungicida Mínima (CFM) do OELS apresentou valores que

TABELA 1. Composição química (\%) do óleo essencial das folhas de Lippia sidoides Cham.

\begin{tabular}{lcccc}
\hline Composto & TR $^{1}$ & IK Lit. $^{2}$ & IK Calc. $^{3}$ & ( \%) \\
\hline p-cimeno & 4.231 & 1025 & 1020 & 5.33 \\
1,8-cineol & 4.432 & 1031 & 1043 & 1.68 \\
Y-terpineno & 5.001 & 1060 & 1081 & 1.31 \\
Éter metil carvacrol & 9.722 & 1164 & 1194 & 3.01 \\
Timol & 11.803 & 1290 & 1288 & 84.95 \\
Carvacrol & 12.693 & 1299 & 1332 & 0,41 \\
$\beta-$ cariofileno & 15.1 & 1418 & 1439 & 1.17 \\
\hline TOTAL & & & 97.86 \\
\hline
\end{tabular}

TR - Tempo de Retenção; IK Lit.- Índice Kovats encontrados na literatura; IK Calc. - Índice Kovats calculados; \% - porcentagem 
TABELA 2. Concentração Inibitória Mínima (CIM) do óleo essencial Lippia sidoides Cham. e do timol.

\begin{tabular}{rcccc}
\hline \multicolumn{5}{c}{ MICRO-ORGANISMOS } \\
\hline CK 01 & CK 02 & CA 62 & CT 20 \\
\hline TIMOL & 128 & 64 & 256 & 128 \\
\hline
\end{tabular}

OELS - óleo essencial de Lippia sidoides Cham. CK - Candida krusei; CA - Candida albicans; CT - Candida tropicalis. Valores informados em $\mu \mathrm{g} / \mathrm{mL}$.

TABELA 3. Concentração Fungicida Mínima (CFM) do óleo essencial Lippia sidoides Cham. e do timol.

\begin{tabular}{ccccc}
\hline \multicolumn{5}{c}{ MICRO-ORGANISMOS } \\
\hline CK 01 & CK 02 & CA 62 & CT 20 \\
\hline TIMOL & 256 & 128 & 512 & 256 \\
\hline
\end{tabular}

OELS - óleo essencial de Lippia sidoides Cham. CK - Candida krusei; CA - Candida albicans; CT - Candida tropicalis. Valores informados $\mathrm{em} \mu \mathrm{g} / \mathrm{mL}$.

variaram de 128 a $512 \mu \mathrm{g} / \mathrm{mL}$ enquanto para o timol a concentração fungicida variou entre 64 e $128 \mu \mathrm{g} /$ $\mathrm{mL}$, como pode ser visto na (tabela 3 ). Os resultados obtidos indicam que tanto o OELS quanto o timol são produtos de efeito antifúngico significativo e de relevância clínica.

A técnica do microcultivo para fungos foi empregada na determinação do efeito dos produtos sobre a transição morfológica das amostras de Candida, utilizando-se o meio sólido ágar-arroz, meio empobrecido apropriado capaz de causar stressamento em leveduras, por inanição, tendo como consequência a emissão de hifas visando a busca de nutrientes. Neste estudo, ao meio de cultura ágar-arroz, foram adicionadas as emulsões do óleo essencial nas concentrações correspondentes às concentrações CIM e CIM x 2 . O controle de crescimento e um controle de DMSO também foram realizados.

Em relação à interferência do óleo essencial sobre a micromorfologia fúngica, por meio da análise em microscopia, nos experimentos controle, verificaram-se as características morfológicas inerentes a cada espécie, deste modo, comprovando a viabilidade celular e a capacidade normal de morfogênese das mesmas. As imagens obtidas nos testes e aqui apresentadas (Figura 1) constam apenas do controle e da demonstração do efeito dos produtos frente às leveduras, quando estes causaram alguma alteração.

Quando cultivadas em meio de cultura acrescido do OELS, as cepas CK LMBM 01 e CT LM 20 apresentaram alterações no seu potencial dimórfico, não tendo sido registrada a presença de hifas e pseudohifas, conforme visualizado na (Figura
1). As alterações foram bastante semelhantes em todas as concentrações, entretanto podese observar um efeito de inibição diretamente proporcional à concentração. O óleo essencial não interferiu na transição morfológica das linhagens CA LM 62 e CK LMBM 02.

As cepas CK LMBM 01 e CA LM 62 cultivadas na presença do timol, apresentaram alterações morfológicas em todas as concentrações ensaiadas, não havendo registro de hifas ou pseudohifas, como pode ser observado na Figura 1. Já a cepa CT 20 , quando cultivada na presença do monoterpeno, sofreu uma redução no processo de morfogênese, diminuindo a emissão de brotos, apenas quando a concentração inibitória foi duplicada (CIM $\times 2)$, revelando que o efeito acentuase à medida em que se eleva a concentração. Assim como o óleo, o timol também não influenciou a transição morfológica das leveduras de $C$. krusei LMBM 02.

\section{DISCUSSÃO}

O potencial antifúngico da espécie $L$. sidoides tem sido revelado em estudos realizados utilizando-se diferentes metodologias. Para expressar inicialmente o seu potencial antifúngico, Farias et al. (2012) testou um extrato etanólico da planta através de difusão em disco verificando que ela foi efetiva contra 45 estirpes de espécies de Candida. Batista et al. (2013), utilizando o método de difusão em Agar, verificou que tanto o óleo quanto o extrato da planta exibiram efeito contra linhagens de C. albicans C. guilliermondii C. parapsilosis e C. tropicalis. O óleo essencial de $L$. sidoides apresentou 
FIGURA 1. Alterações morfológicas observadas através de microcultivo das linhagens de Candida na presença e na ausência de Óleo Essencial de Lippia sidoides e timol.

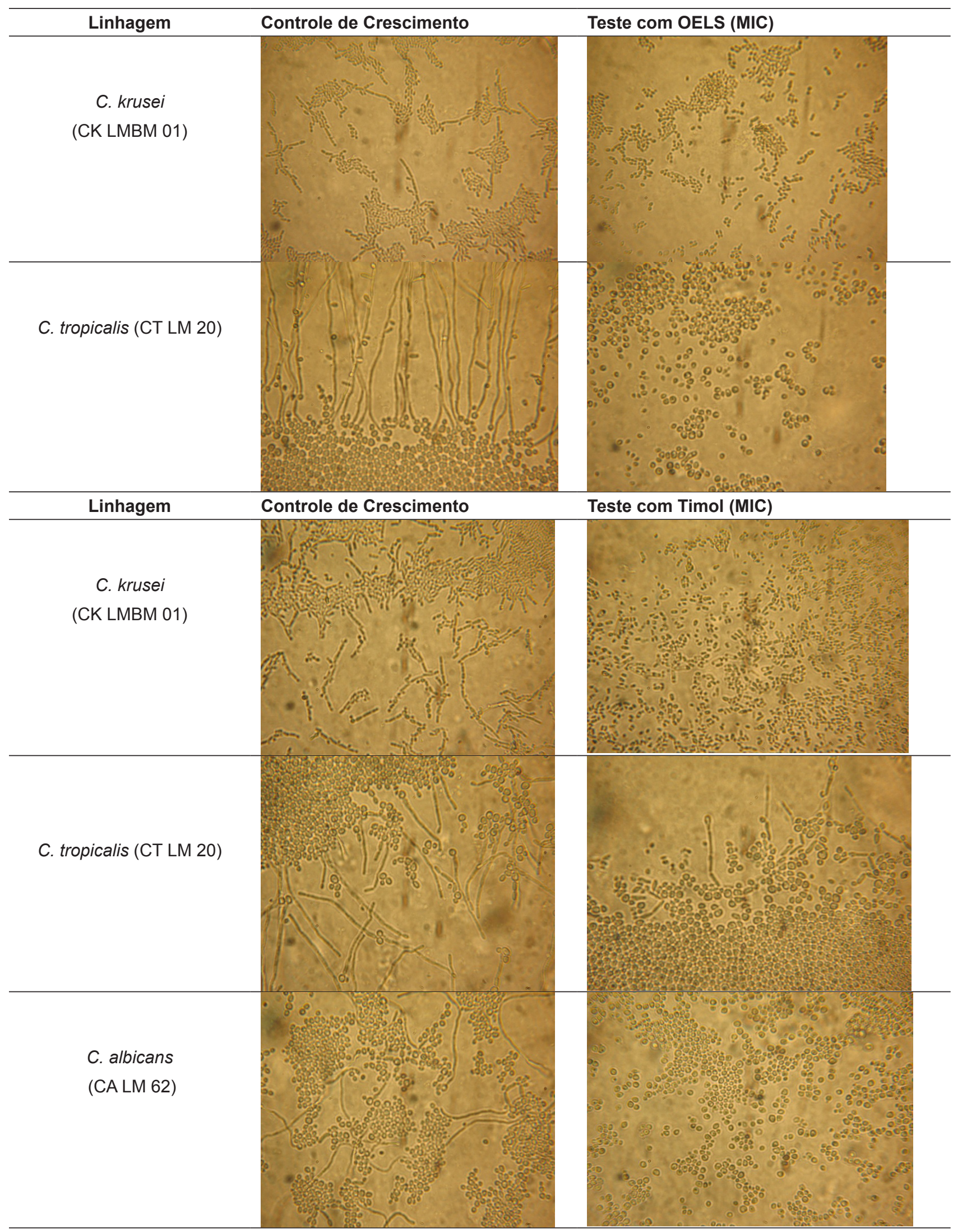

OELS - óleo essencial de Lippia sidoides; LM: Laboratório de Micologia; LMBM: Laboratório de Microbiologia e Biologia Molecular; micrografia realizada através de microscopia óptica em objetiva de 40X; imagem fotográfica captada com zoom de 4X em câmera digital. 
atividade antifúngica contra cepas de Candida spp. e Microsporum canis em ensaios realizados por Fontenelle et al. (2007). Em um estudo comparativo sobre atividade antimicrobiana do óleo essencial e seus componentes majoritários, timol e carvacrol, contra diferentes espécies de bactérias e contra o fungo $C$. albicans, utilizando a diluição de caldo e ensaios de difusão em disco, Botelho et al. (2007) demonstrou que os três compostos exibiram atividade antibacteriana e antifúngica, sendo os melhores resultados atribuídos ao timol e ao carvacrol.

Análises fitoquímicas do óleo essencial de $L$. sidoides realizadas em estudos anteriores revelaram a presença de constituintes como timol, carvacrol, a-pineno, p-pineno, 1,8 cineol, - $y$-terpineno, p-metadieno, metil-timol, metilcarvacrol, linalol, 4-terpineole, -yelemeno (Matos \& Oliveira, 1998; Leal et al., 2003). Nestas análises o timol tem sido reconhecido como o composto majoritário e pesquisas indicam que este pode estar relacionado com a propriedade antibacteriana e antifúngica do óleo essencial de $L$. sidoides (Matos \& Oliveira, 1998).

A atividade dos óleos essenciais sobre bactérias Gram-positivas e fungos parece ocorrer de forma semelhante. Os constituintes dos óleos destroem a membrana citoplasmática e parede celular de bactérias e fungos, isso resulta em extravasamento do citoplasma e sua coagulação, além de inibir a respiração celular (Cox et al., 2000). A ação de óleos essenciais contra fungos pode ser observada por meio das alterações morfológicas, que podem ser visualizadas tanto macroscopicamente como microscopicamente (Kalemba \& Kunicka, 2003).

Segundo critérios propostos por Sartoratto et al (2004), óleos essenciais com CIM entre valores de 50 e $500 \mu \mathrm{g} / \mathrm{mL}$ são considerados com forte atividade antimicrobiana, com CIM entre 600 a 1500 $\mu \mathrm{g} / \mathrm{mL}$ possuem atividade moderada e CIM acima de $1500 \mu \mathrm{g} / \mathrm{mL}$ são considerados com atividade fraca. Neste contexto, os resultados obtidos indicam que o óleo essencial de L. sidoides pode ser considerado como produto natural de forte atividade antimicrobiana.

O óleo essencial obtido das folhas de L. sidoides exibe rendimento bastante variável, algumas vezes podendo chegar próximo a $6 \%$, e possui como características sabor fortemente picante e acentuado odor de timol (Souza et al., 2004). Na maioria dos estudos apresenta como composto majoritário o timol, um monoterpeno fenólico (Craveiro et al., 1981; Matos \& Oliveira, 1998; Fontenelle et al., 2007; Delfino, 2012; Veras et al., 2012). O mesmo componente foi encontrado na CG-EM realizada neste estudo.
Outros componentes podem ser encontrados geralmente em concentrações menores, entre eles, $\beta$-cariofileno, Etil-metil-carvacrol, mirceno, p-cimeno, p-cineol e $y$-terpineno (Matos et al., 1998; Fontenelle et al., 2007; Monteiro et al., 2007; Cavalcanti et al., 2010; Veras et al., 2012). A maioria destes compostos também foram encontrados no OELS.

A formação de hifa e pseudohifa por fungos do gênero Candida são descritos como fatores de virulência, pois essas estruturas representam uma barreira para fagocitose impedindo sua eliminação no tecido epitelial. Mudanças morfológicas estão agregadas à patogenicidade do micro-organismo, e acredita-se que fatores ambientais possam alterar o estado fisiológico das leveduras comensais, induzindo alterações morfogenéticas que resultam na formação de micélio, o qual está associado com a evolução dos estados patológicos (Romani et al., 2003; Whiteway \& Oberholzer, 2004). Essas mudanças causam implicações na patogênese e no diagnóstico das infecções causadas por esses micro-organismos, e ocorrem tanto in vivo quanto in vitro. Nos testes in vitro, a forma micelial ou de pseudo-micélio, é influenciada por fatores ambientais. O dismorfismo de fungos do gênero Candida spp foi observado em infecções ativas, com predominância da forma blastospórica (leveduriforme), estas formas estão associadas com a colonização inicial ao passo que a forma micelial (pseudohifas) encontra-se associada com a invasão do fungo (Lo et al., 1997; Romani et al., 2003). Portanto, alterações na micromorfologia, como a inibição da formação de pseudohifas que ocorreram com o uso do OELS e do timol, são importantes para impedir o crescimento, a viabilidade e principalmente a virulência dos fungos.

Alterações na morfologia da célula fúngica causadas por óleos essenciais podem estar relacionadas com a interferência dos seus constituintes químicos sobre enzimas responsáveis pela biossíntese ou manutenção da parede celular, afetando o crescimento e morfogênese fúngica (Zambonelli et al., 1996; Debillerbeck et al., 2001). Tanto o OELS quanto o timol provocaram inibição da formação de pseudohifas, que são fatores de virulência importantes no desenvolvimento das candidíases, sendo o efeito de inibição diretamente proporcional à concentração. Dessa maneira, na cepa CK LMBM 01, a inibição pode ter sido devido ao timol, que isoladamente, conseguiu impedir a formação das pseudohifas. Entretanto para a cepa CT LM 20, algum outro fitoconstituinte do óleo foi responsável pela ação antifúngica, uma vez que não foi observada a mesma atividade no ensaio com o timol. Em relação a cepa CA 62, enquanto o timol conseguiu inibir a formação das pseudohifas, o OELS não apresentou nenhum efeito sobre

Rev. Bras. PI. Med., Campinas, v.17, n.4, supl. II, p.836-844, 2015. 
esta, sugerindo que possivelmente algum outro fitoconstituinte presente no óleo tenha interagido com o timol e modificado o seu potencial de ação antifúngica.

\section{CONCLUSÃO}

O óleo essencial obtido das folhas de $L$. sidoides, bem como o seu composto majoritário timol, apresentou potencial antiúngico expressivo com relevância clínica para todas as cepas estudadas, causando inclusive efeito fungicida. Ambos os produtos causaram alterações morfológicas nas células fúngicas, provocando inibição ou redução da emissão de hifas e pseudohifas, um de seus principais fatores de virulência, responsável por seu potencial invasivor de tecidos. Outros estudos entretanto, serão necessários no sentido de investigar com maior profundidade o mecanismo de ação destes produtos naturais sobre a morfologia das leveduras do gênero Candida.

\section{REFERÊNCIAS}

ABDELGALEIL, S.A.M. et al. Bioactivity of two major constituents isolated from the essential oil of Artemia judaica L. Biosource Technology, v. 99, p. 5947-50, 2008.

ADAMS, R. P. Identification of Essential Oil Components by Gas Chromatography/Quadrupole Mass Spectroscopy. Carol Stream, Illinois: Allured Publishing Corporation, 2001.

BAKKALI, F. et al. Biological effects of essential oils: a review. Food Chemistry and Toxicology, v.46, p. 446-75, 2008.

BATISTA, R. S. A. et al.. Atividade antifúngica de alecrimpimenta (Lippia sidoides Cham.) sobre Candida spp. Revista Agropecuária Técnica, v. 34, p. 40-49, 2013.

BOTELHO, M.A. et al. Antimicrobial activity of the essential oil from Lippia sidoides, cavacrol and thymol against oral pathogens. Brazilian Journal Medical and Biological. Research. v. 40, p. 349-56, 2007.

CAVALCANTI, S.C.H. et al. Composition and acaricidal activity of Lippia sidoides essential oil against twospotted spider mite (Tetranychus urticae Koch). Bioresource Technology, v. 101, p. 829-32, 2010.

CLEELAND, R.; SQUIRES, E. Evaluation of new antimicrobials "in vitro" and in experimental animal infections. In: LORIAN, V.M.D. Antibiotics in laboratory medicine. $3^{\mathrm{a}}$ ed. Baltimore: Williams \& Wilkins, 1991, p. 739-88.

COUTINHO, H.D.M. et al. In vitro anti-staphylococcal activity of Hyptis martiusii Benth against methicillinresistant Staphylococcus aureus-MRSA strains. Revista Brasileira de Farmacognosia. v. 18, p. 670-5, 2008.

COX, S.D. et al. The mode of antimicrobial action of the essential oil of Melaleuca alternifolia (tea tree oil). Journal of Applied Microbiology, v.88, p.170-5, 2000. CRAVEIRO, A.A. et al. Essential oils from brazilian
Verbenaceae. Genus Lippia. Journal of Natural Products, v. 44, p. 598-601, 1981.

DEBILLERBECK, V.G. et al. Effect of Cymbopogon nardus (L) W. Watson essential oil on the growth and morphogenesis of Arpergillus niger. Canadian Journal of Microbiology, v.47, p. 17-9, 2001.

DELFINO, M.M.S. Óleos essenciais no controle de Tetranychus evansi Baker \& Pritchard e Tetranychus urticae Koch (acari: tetranychidae). 2012. 85f. Dissertação (Mestrado em Bioprospecção Molecular) -Universidade Regional do Cariri, Crato.

DIGNANI, M.C. et al. Candida. In: ANAISSIE, E. et al. Medical Mycology. 1ed. Filadélfia: 2003, p. 195-239.

ELLOF, J.N. A sensitive and quick microplate method to determined the minimal inhibitory concentration of plant extracts for bacteria. Planta Medica, v. 64, p. 711-3, 1998.

FONTENELLE, R. et al. Chemical composition, toxicological aspects and antifungal activity of essential oil from Lippia sidoides. Journal of Antimicrobial Chemotherapy, v. 59, p. 934-40, 2007.

GOTTLIEB, O,R. Modified distillation trap. Chemist Analyst, v.49, p.114-6, 1960.

HADACEK, F.; GREGER, H. Testing of antifungical natural products: methodologies, comparability of results and assay choise. Phytochemical Analysis, v. 11, p.13747, 2000.

JAVADPOUR, M.M. et al. De novo antimicrobial peptides with low mammalian cell toxicity, Journal of Medicinal Chemistry, v. 39, p. 3107-13, 1996.

KALEMBA, D.; KUNICKA, A. Antibacterial and antifungal properties of essential oils. Current Medicinal Chemistry, v. 10, p. 813-29, 2003.

KURTZMAN, C.P; FELL, J.W. 1998. Definition, classification and nomenclature of the yeasts. In: The Yeasts, A Taxonomic Study, KURTZMAN, C.P.; FELL, J.W. (eds.) 4th edn. Elsevier Science B.V.; Amsterdam.

LEAL, L.K.A.M. et al. Análise do timol por CLAE na tintura de Lippia sidoides Cham. (alecrim-pimenta) produzida em diferentes estágios de desenvolvimento da planta. Revista Brasileira de Farmacognosia, v.13, Suplemento, p. 09-11, 2003.

LO, H.J. et al. Nonfilamentous C. albicans mutants are avirulent. Cell, v. 90, p. 939-49, 1997.

LORENZI, H.; MATOS, F.J.A. Plantas medicinais no Brasil; nativas e exóticas. 1ed Nova Odessa: instituto Plantarum, 2002. 512p.

MATOS, F.J.A. et al. Essential oil of Lippia sidoides Cham. (Verbenaceae) a medicinal aromatic schrub from Northeast Brasil. Journal Essential Oil Research, 1998.

MATOS, F.J.A. Fármacias vivas: sistemas de utilização de plantas medicinais em projetos para pequenas comunidades. 4. ed. Fortaleza: UFC. 267p. 2002.

MATOS, F.J.A.; OLIVEIRA, F. Lippia sidoides Cham. - Farmacognosia, química e farmacologia. Revista Brasileira de Farmácia, v.79, p. 84-7, 1998.

MICTHELL, T. G. Micologia médica. In: JAWETZ, MELNICK E ADELBERG: Microbiologia Médica: um livro médico Lange/ Geo. F. Brooks...[et al]. - 24.ed. - Rio de Janeiro: McGraw-Hill Interamericana do Brasil Ltda., 2009.

MONTEIRO, M. V. B. et al. Topical anti-inflammatory, 
gastroprotective and antioxidant effects of essential oil of Lippia sidoides Cham leaves. Journal of Ethnopharmacology, v. 111, p. 378-82, 2007.

NCCLS. Método de Referência para Testes de Diluição em Caldo para a Determinação da Sensibilidade a Terapia Antifúngica das Leveduras; Norma Aprovada - Segunda Edição. NCCLS document M27-A2 [ISBN 1-56238-469-4]. NCCLS, 940 West Valley Road, Suite 1400, Wayne, Pennsylvania 19087-1898 Estados Unidos, 2002.

ROMANI, L.; et al. Adaptation of Candida albicans to the host environment: the role of morphogenesis in virulence and survival in mammalian hosts. Current Opinion in Mcrobiology, v. 6, p. 338-43, 2003.

SARTORATTO, A. et al. Composition and antimicrobial activity of essential oils from aromatic plants used in Brazil. Brazilian Journal of Microbiology, v. 35, p. 275-80, 2004.

SIDRIM, J. J. C.; ROCHA, M. F. G. Micologia médica à luz de autores contemporâneos. Rio de Janeiro: Guanabara Koogan. 2010, 388 p.

SIMÕES, C. M. O.; SCHENKEL, E. P.; GOSMANN, G.; MELLO, J. C. P.; MENTZ, L. A.; PETROVICK, P.R. Farmacognosia: da planta ao medicamento. 5 ed. Porto Alegre/Florianópolis:Editora da Universidade
UFRGS / Editora da UFSC, 2004.

SOUZA, M. P. et al. Constituintes químicos ativos e propriedades biológicas de plantas medicinais brasileiras. $2^{a}$ Ed. Fortaleza: Editora UFC, p.51-85, 2004.

SOUZA, E. L.; et al., Effectiveness of Origanum vulgare $L$. essential oil to inhibit the growth of food spoiling yeasts. Food Control, v. 18, p. 409-13, 2007.

SHADOMY, S.; ESPINEL-INGROFF, A.; CARTWRIGHT, R. Laboratory studies with antifungal agents: susceptibility test and bioassay In: LENNETTE, E. H.; BALLOWS, A.; HAUSLERS JR. V.; SHADOMY, $\mathrm{H}$. J. (Eds). Manual of clinical microbiology. 4. ed. Washington: American Society of Microbiology, 1985. p.991-999.

VERAS, H. N. H. et al. Synergistic antibiotic activity of volatile compounds from the essential oil Lippia sidoides and thymol. Fitoterapia, v. 83, p. 1-5, 2012.

WHITEWAY, M.; OBERHOLZER, U. Candida morphogenesis and host-pathogen interactions. Current Opinium in Microbiology, v. 7, p. 350-7, 2004.

ZAMBONELLI, A. et al. Effects of essential oil on phytopathogenic fungi. Phytopathology, v. 144, p. 491-4, 1996. 